\title{
Mechanism of diastolic rumble and presystolic murmur in mitral stenosis
}

\author{
Pavlos Toutouzas, Antonios Koidakis, Anastasios Velimezis, and Demetris Avgoustakis \\ From the Department of Cardiology, Medical School of the University of Athens - Hippokration Hospital
}

The mechanism of the murmurs heard in mitral stenosis was studied in 61 patients by using simultaneous recordings of the mitral valve echocardiogram, phonocardiogram, and apex cardiogram.

It was observed that: (a) the diastolic rumble began just after the $E$ point of the echocardiogram, clearly related to the diastolic closure of the valve, and was never recorded during the opening motion of the valve, which in 49 patients was completed ( $E$ point) 20 to 60 msec after the opening snap; (b) the presystolic murmur was recorded at the time the mitral valve was closing during preisometric contraction of the left ventricle.

It is suggested that both murmurs probably originate from impact between increased velocity of forward blood flow and the backward closing motion of the mitral valve. This mechanism explains (I) the frequently noted gap between the opening snap and the onset of the diastolic rumble; (2) the reduction in amplitude or disappearance of the diastolic rumble in calcified mitral stenosis; and (3) the occasional presence of a presystolic murmur in atrial fibrillation.

The mechanism of the diastolic rumble and presystolic murmur in mitral stenosis is still unclear. Until recently these murmurs were attributed to the increased blood flow velocity through the narrowed mitral orifice, caused by the diastolic gradient between the left atrium and the left ventricle. However, in the past few years it has been thought that mitral valve motion itself is responsible for certain mitral diastolic murmurs. In combined cineangiocardiographic and phonocardiographic studies (Criley, Feldman, and Meredith, 197I ; Criley and Hermer, 1971), it was observed that the presystolic murmur was related to the closing motion of the mitral leaflets; it is suggested that the progressive decrease in orifice size, engendered by the closure of the valve, is the cause of the murmur. This observation was confirmed in the echocardiographic studies of Fortuin and Craige (1973). These investigators, in addition, noted a similar time relation between the diastolic closing motion of the anterior mitral leaflet and the appearance of middiastolic murmurs heard in aortic regurgitation (Austin-Flint murmur), mitral regurgitation, and congenital heart diseases with large left-to-right shunt. They suggested that in such cases the closing motion of the mitral valve against an increased velocity of forward flow might be a contributory

Received 25 March 1974. factor in the production of these murmurs (Fortuin and Craige, 1972, 1973).

This study investigates the pathogenesis of the presystolic murmur and the diastolic rumble in mitral stenosis by using simultaneous recordings of the mitral valve echocardiogram, phonocardiogram, and apex cardiogram.

\section{Subjects and methods}

Studies were made on 61 patients, 12 men and 49 women, whose ages ranged from 16 to 65 years (average 42 ). In all patients the physical findings of mitral stenosis were present and the mitral valve echocardiogram demonstrated an abnormally slow diastolic closure from $\mathrm{E}$ to $\mathrm{F}$, of less than $35 \mathrm{~mm}$ per second (Edler, 1967). The stenosis was confirmed by cardiac catheterization and angiocardiography; in 12 patients it was combined with insignificant mitral regurgitation. In 8 cases the mitral valve was calcified. Twenty-five patients were in sinus rhythm and the remaining 36 in atrial fibrillation. Echocardiograms of the mitral valve were obtained using a Hewlett-Packard 7214A ultrasound device, with attached Polaroid camera for film recording. Phonocardiograms from the apex, where the murmurs were best heard, and left ventricular apex cardiograms were obtained using an Electronics for Medicine multichannel recorder and transducer (PS-IB). The gated mitral valve echo signal and lead II of the electrocardiogram were recorded simultaneously with the phonocardiogram and apex cardiogram. The recordings 
were made at a paper speed of $100 \mathrm{~mm}$ per second with time lines at $20 \mathrm{msec}$ intervals.

In each patient the morphology of the diastolic rumble as well as the time relation of this murmur and the opening snap to the echocardiographic curve of the anterior mitral leaflet were studied. The morphology of the presystolic murmur and its time relation to the $P$ and $Q$ waves of the electrocardiogram, the $C$ point of the apex cardiogram, and echocardiographic closing curve of the mitral valve, were also defined.

\section{Results}

\section{A: Opening snap and diastolic rumble (Tables 1 and 2)}

The opening snap was recorded 40 to $120 \mathrm{msec}$ after the aortic component of the second sound. In patients with a calcified mitral valve the opening snap was inconspicuous. In 49 patients it coincided with the $\mathbf{X}$ point of the echocardiogram in which an abrupt deceleration of the opening valve motion occurred (Fig. I, 2, 3, 6, and 7). In these patients the interval X-E on the echocardiogram varied from 20 to $60 \mathrm{msec}$. In the remaining 12 patients there was no point $X$; in these case the valve rapidly moved to the completely open position, i.e. the $\mathbf{E}$ point of the echocardiogram, which coincided with the opening snap (Fig. 4 and 5).

The diastolic rumble was decrescendo in type and its vibrations were always greater in sinus rhythm than in atrial fibrillation. In the patients with a calcified mitral valve this murmur was quiet or virtually absent (Fig. 6). The diastolic rumble always began immediately after the mitral valve was completely open, i.e. after the $\mathrm{E}$ point of the echocardiogram. Thus, in 12 patients the murmur began at the time the opening snap was recorded, and in 49 patients 20 to $60 \mathrm{msec}$ after the opening snap. The diastolic slope of the echocardiogram in patients with a pliable mitral valve frequently presented distortions or 'dents' (Fig. 2, 4, and 5) which were not observed in cases with calcified valve.

TABLE I Data derived from 25 patients with mitral stenosis in sinus rhythm

\begin{tabular}{|c|c|c|c|c|c|c|c|c|c|c|c|}
\hline \multirow{2}{*}{$\begin{array}{l}\text { Case } \\
\text { No. }\end{array}$} & \multirow[t]{2}{*}{ Sex } & \multirow{2}{*}{$\begin{array}{l}\text { Age } \\
(y r)\end{array}$} & \multirow{2}{*}{$\begin{array}{l}\text { Heart } \\
\text { rate }\end{array}$} & \multirow{2}{*}{$\begin{array}{l}\text { Pre- } \\
\text { systolic } \\
\text { murmur }\end{array}$} & \multirow{2}{*}{$\begin{array}{l}P R \\
\text { interval }\end{array}$} & \multirow{2}{*}{$\begin{array}{l}P \text { wave } \\
\text { - PSM } \\
\text { onset }\end{array}$} & \multirow{2}{*}{$\begin{array}{l}P S M \text { onset } \\
-C(A C G) \\
(m s e c)\end{array}$} & \multirow{2}{*}{$\begin{array}{l}\text { A2-OS } \\
\text { interval } \\
\text { (msec) }\end{array}$} & \multicolumn{3}{|c|}{ Mitral valve echocardiograms } \\
\hline & & & & & & & & & $\begin{array}{l}D-X \\
\text { interval } \\
\text { (msec) }\end{array}$ & $\begin{array}{l}X-E \\
\text { interval } \\
\text { (msec) }\end{array}$ & $\begin{array}{l}\text { Diastolic } \\
\text { slope } \\
\text { rate } \\
(\mathrm{mm} / \mathrm{sec})\end{array}$ \\
\hline I & $\mathrm{F}$ & 38 & 67 & C-D & 240 & 180 & 60 & 70 & $\star$ & $\star$ & 15 \\
\hline 2 & $\mathbf{F}$ & 40 & 61 & C-D & 240 & 140 & 130 & 70 & 20 & 20 & 30 \\
\hline 3 & $\mathbf{F}$ & 38 & 75 & C-D & 240 & 160 & 120 & 40 & 20 & 40 & 15 \\
\hline 4 & $\mathbf{M}$ & 48 & 67 & C & 200 & 230 & 0 & 60 & 40 & 60 & 15 \\
\hline 5 & $\mathbf{F}$ & 39 & 64 & C & 160 & 160 & 40 & 60 & 30 & 60 & 25 \\
\hline 6 & $\mathbf{F}$ & 40 & 65 & C & 140 & 140 & 40 & 70 & 40 & 50 & 20 \\
\hline 7 & $\mathbf{M}$ & 34 & 74 & C & 180 & 220 & 0 & 90 & 40 & 60 & 22 \\
\hline 8 & $\mathbf{F}$ & 35 & 89 & C & 180 & 160 & 40 & 80 & $\star$ & $\star$ & 28 \\
\hline 9 & $\mathbf{F}$ & 32 & 78 & C & 140 & 130 & 40 & 70 & $\star$ & $\star$ & 27 \\
\hline 10 & $\mathbf{M}$ & 53 & 63 & C & 180 & 220 & 0 & 65 & 40 & 50 & 8 \\
\hline II & $\mathbf{F}$ & 24 & 100 & C & 140 & 150 & 20 & 100 & 40 & 40 & 35 \\
\hline 12 & $\mathbf{F}$ & 32 & 70 & C & 160 & 160 & 20 & 70 & 40 & 60 & 15 \\
\hline 13 & $\mathbf{M}$ & 43 & 65 & C & 140 & 180 & 0 & 80 & $\star$ & $\star$ & 20 \\
\hline 14 & $\mathbf{F}$ & 37 & 72 & C & 180 & 220 & 0 & 70 & 40 & 20 & 15 \\
\hline 15 & F & 16 & 80 & C & 180 & 140 & 60 & 60 & 20 & 30 & 14 \\
\hline 16 & $\mathrm{~F}$ & 33 & 61 & $\mathrm{C}$ & 140 & 140 & 40 & 70 & $\star$ & $\star$ & 25 \\
\hline 17 & $\mathbf{F}$ & 42 & 56 & C-D & 240 & 220 & 60 & 120 & $\star$ & $\star$ & 35 \\
\hline 18 & F & 50 & 80 & C & 160 & 160 & 30 & I 10 & 30 & 30 & 26 \\
\hline 19 & $\mathbf{F}$ & 47 & 65 & C & 140 & 180 & 0 & 80 & $\star$ & $\star$ & 18 \\
\hline 20 & $\mathbf{M}$ & 42 & 86 & C & 210 & 210 & 30 & 60 & 40 & 50 & 12 \\
\hline 21 & $\mathbf{F}$ & 24 & 82 & C & 200 & 160 & 140 & 80 & 30 & 60 & 29 \\
\hline 22 & $\vec{F}$ & 36 & 75 & C & 180 & 180 & 40 & IIO & 40 & 40 & 26 \\
\hline 23 & $\mathbf{F}$ & 35 & 73 & C & 140 & 160 & 20 & 100 & 30 & 40 & 22 \\
\hline 24 & $\mathrm{~F}$ & 16 & 58 & C & 160 & 160 & 30 & 50 & 40 & 60 & 15 \\
\hline 25 & $\mathbf{F}$ & 33 & 65 & C & 140 & 160 & 0 & 75 & 30 & 40 & 20 \\
\hline
\end{tabular}

C-D $=$ Crescendo-decrescendo.

C $=$ Crescendo.

$\star=$ Patients with no $X$ point on the echocardiogram; in these cases the opening motion of the valve was completed rapidly in one phase D-E. 


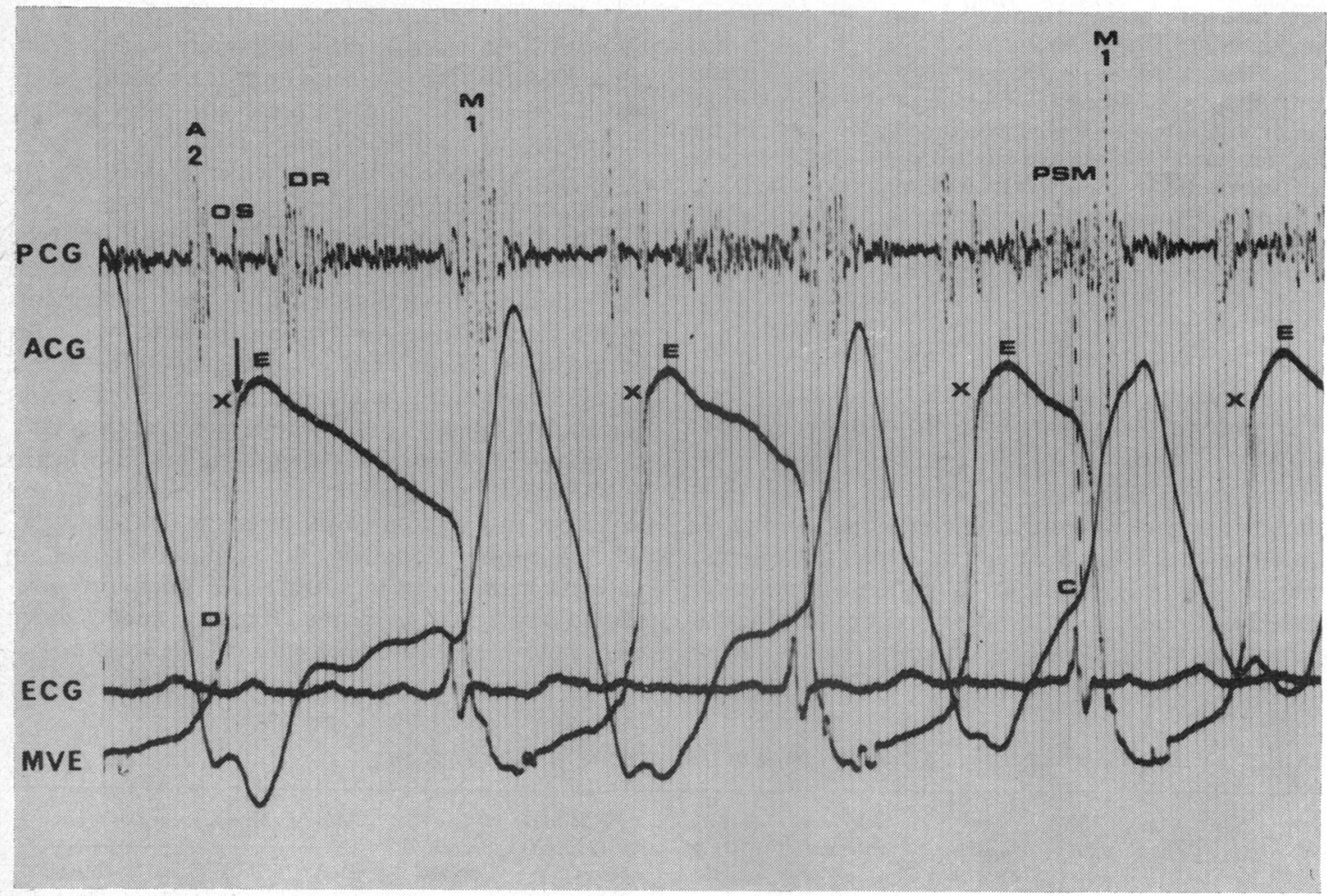

FIG. I Mitral stenosis with atrial fibrillation. The mitral valve echocardiogram (MVE) shows two distinct phases of the opening motion of the anterior leaflet: a rapid one $(D-X)$ lasting about $40 \mathrm{msec}$ and a slow one $(X-E)$ lasting about $60 \mathrm{msec}$. The opening snap (OS) coincides with the $X$ point of the echocardiogram (arrow). The diastolic rumble $(D R)$ appears after the $E$ point, corresponding with the diastolic closing motion of the mitral valve. A presystolic murmur (PSM) appears after short diastolic periods $\left(M_{1}=\right.$ mitral component of the Ist sound: $A_{2}=$ aortic component of the 2 nd sound).

\section{B: Presystolic murmur (Tables 1 and 2)}

This murmur was recorded in all patients with sinus rhythm and in 10 of the 36 with atrial fibrillation (Fig. I, 5, and 7). It was crescendo in type in 21 of the patients with sinus rhythm, beginning 130 to $230 \mathrm{msec}$ after the onset of the $P$ wave of the electrocardiogram. When the PR interval was normal the beginning of the murmur coincided with the onset of the QRS complex. However, in 4 out of 5 patients with a prolonged $P R$ interval the presystolic murmur began before the onset of the QRS complex and was crescendo-decrescendo in type. In atrial fibrillation the presystolic murmur was always crescendo and louder in the cardiac cycles following short diastolic periods (Fig. I and 7). It began after the onset of the QRS complex and its vibrations were always of less amplitude than in sinus rhythm.
The presystolic murmur always began at or just after the peak of the A wave of the echocardiogram of the mitral valve. The progressive increase in amplitude of the crescendo murmur was clearly related to the closing motion of the valve (Fig. I, 5, and 7).

The peak of crescendo-decrescendo murmurs also corresponded with the closing movement on the echocardiogram, and its final vibrations, just before the echocardiographic B point, were of significant amplitude (Fig. 3).

On the apex cardiogram it was found that in patients with sinus rhythm the presystolic murmur began before ( 18 patients) or at the $\mathrm{C}$ point (7 patients), but the peak of the murmur was always noted after this point. In atrial fibrillation the presystolic murmur was constantly recorded after the C point (Fig. 5 and 7 ). 


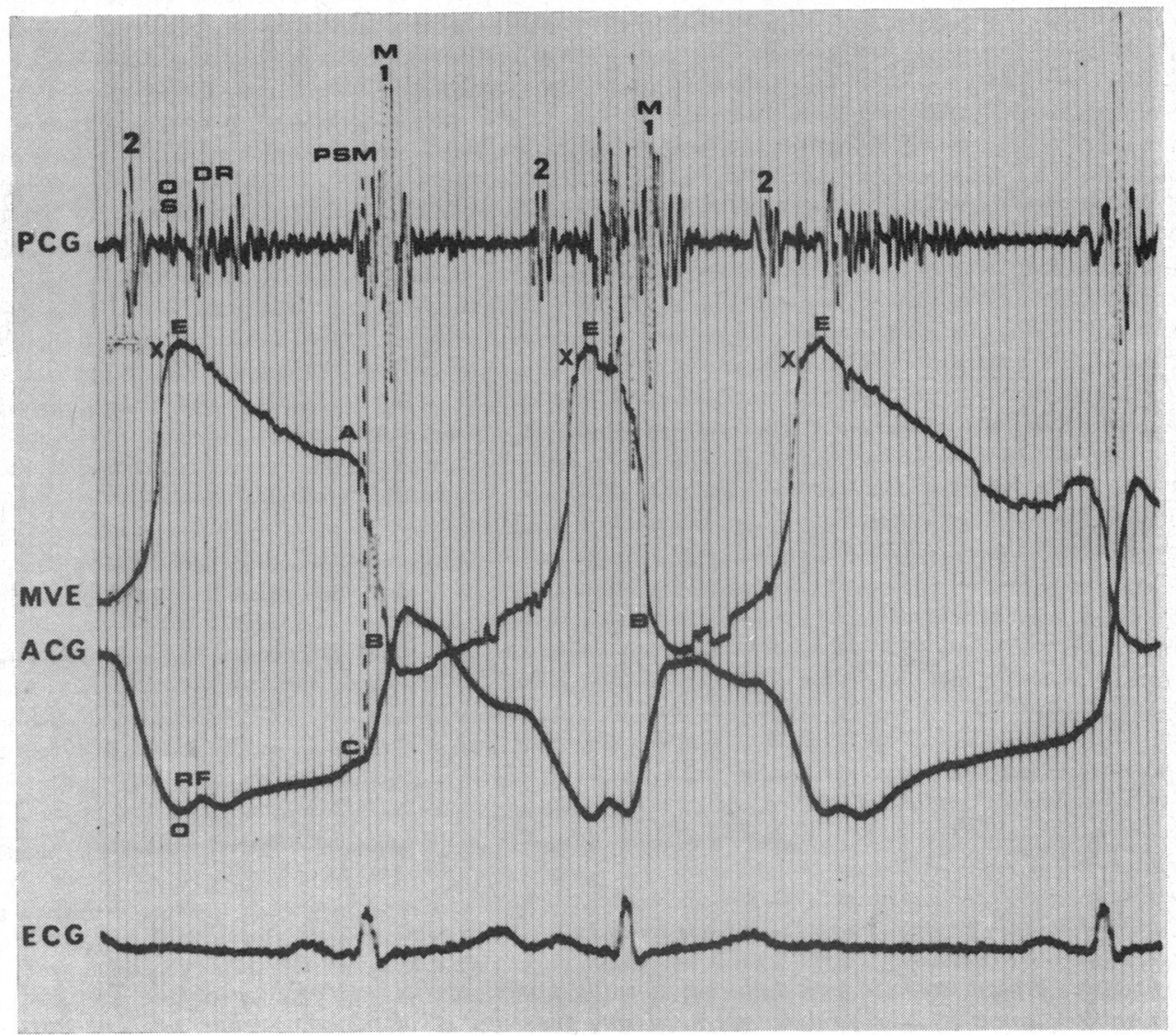

FIG. 2 Mitral stenosis with atrial ectopic beats. The echocardiogram shows an abrupt deceleration of the opening motion of the valve at the $X$ point which coincides with the opening snap. The diastolic rumble appears about $60 \mathrm{msec}$ later and just after the $E$ point. The decrescendo murmur corresponds with the 'dented' diastolic slope of the echocardiogram. A presystolic murmur (PSM) appears at the time of valve closure. The atrial ectopic beat shows that the murmurs are related only to the closing motion of the valve. The presystolic murmur follows the $C$ point of the apex cardiogram (vertical dotted line).

\section{Discussion}

The presence of a presystolic murmur in some cases of mitral stenosis with atrial fibrillation raised doubts about the accuracy of the classical view according to which the atrial contraction is responsible for its genesis. Some authors thought that the presystolic murmur in these cases, usually present in short diastolic periods, was caused by interruption of the diastolic rumble by the following first sound (Ongley, Sprague, and Rappaport, 1955). Others suggested that it was produced by vibrations of a pliable mitral valve (Nichols et al., 1956) or that it was caused by tricuspid closure (Leo and Hultgren, 1959).
Criley et al. (197I) and Criley and Hermer (1971), in cineangiocardiographic and phonocardiographic studies, showed that the presystolic murmur in mitral stenosis was recorded after left atrial systole, while the mitral valve was closing. This observation led them to think that the murmur was caused by increased blood flow velocity through the progressively narrowing mitral orifice during valve closure. Fortuin and Craige (1973) showed a clear relation between the presystolic murmur and the closing movement of the anterior leaflet (after the A wave of the echocardiogram). These authors suggested that, as well as the progressive narrowing of the mitral orifice, the valve motion itself contri- 


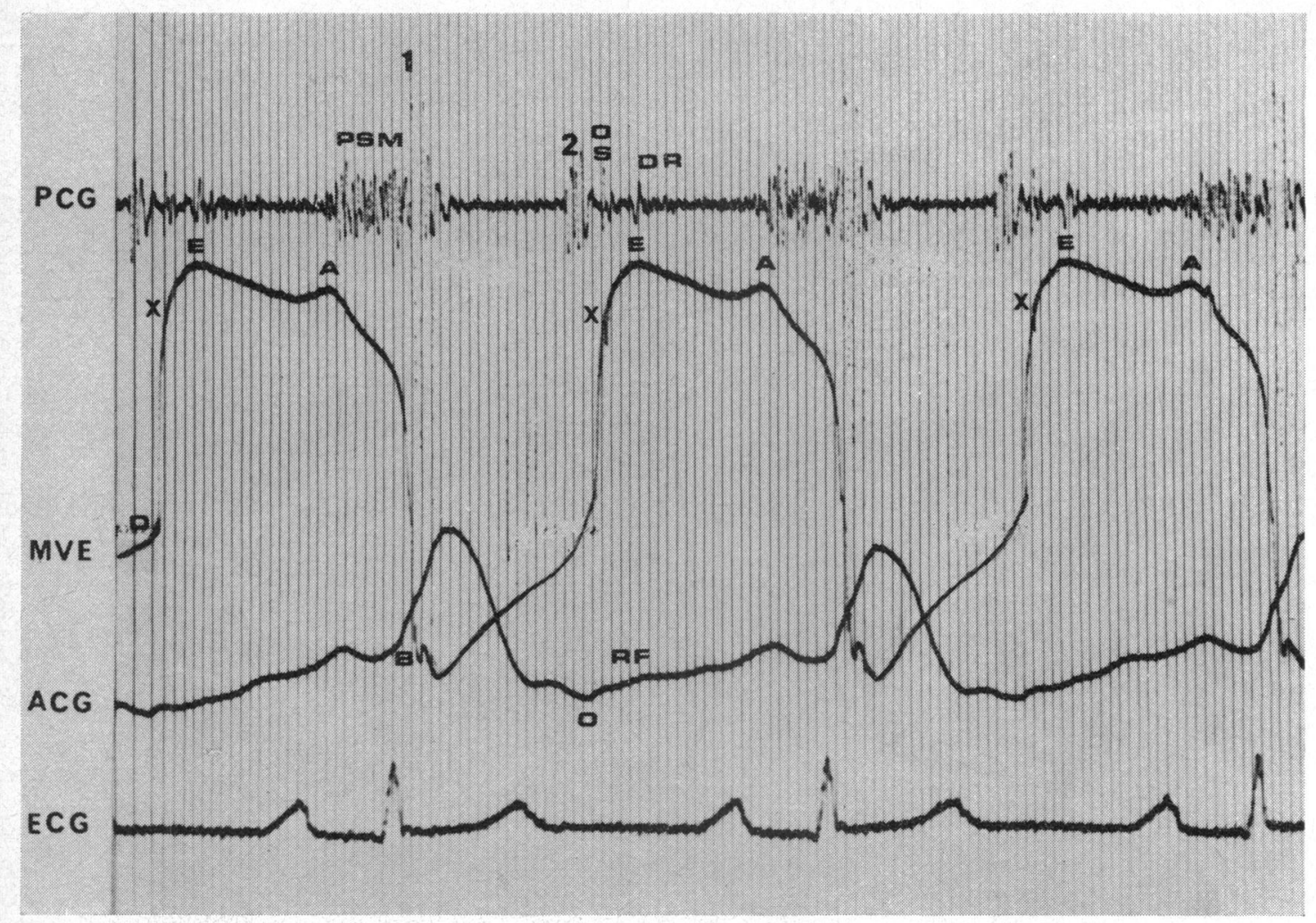

FIG. 3 Mitral stenosis with sinus rhythm and prolonged $P R$ interval (240 msec). The presystolic murmur is clearly related to the closing phase $(A-B)$ of the echocardiogram. The quiet diastolic rumble related to the diastolic slope of the echocardiogram begins about 60 msec after the opening snap. The rapid filling wave $(R F)$ in the apex cardiogram (after the $O$ point) is recorded during the opening motion of the valve $(D-E)$.

buted to the production of the murmur; the movement of the valve leaflets in an opposite direction to the continued forward blood flow provides a mechanism for vortex shedding, i.e. conditions for the production of a murmur.

Our findings are in agreement with the observations of Fortuin and Craige (1973). In all patients the increase of the amplitude of the presystolic murmur occurred with the progressive closing motion of the anterior leaflet. In 5 patients with sinus rhythm and prolongation of the PR interval, in whom the murmur was usually crescendo-decrescendo in type, its maximal amplitude corresponded with the closing phase of the mitral valve echocardiogram. Furthermore, the presystolic murmur or the greater part of it was recorded during preisometric systole. In some patients with sinus rhythm the $C$ point of the apex cardiogram, which is a reliable sign of the onset of left ventricular contraction (Willems, De Geest, and Kesteloot, 1971), coincided with the beginning of the presystolic murmur; in others with sinus rhythm the $\mathrm{C}$ point followed the onset of the murmur, whereas in cases with atrial fibrillation it was always recorded before the onset of the murmur. In addition we found that the $C$ point of the apex cardiogram appeared simultaneously with the beginning of the closing motion of the mitral valve. This is in agreement with the statement of Lakier et al. (1972) that in mitral stenosis the mitral valve starts to close after the onset of the contraction of the left ventricle. These observations suggest that in most cases the presystolic murmur in mitral stenosis is predominantly systolic, and can be well explained by the mechanism postulated by Fortuin and Craige, that is impact of the valve leaflets moving 


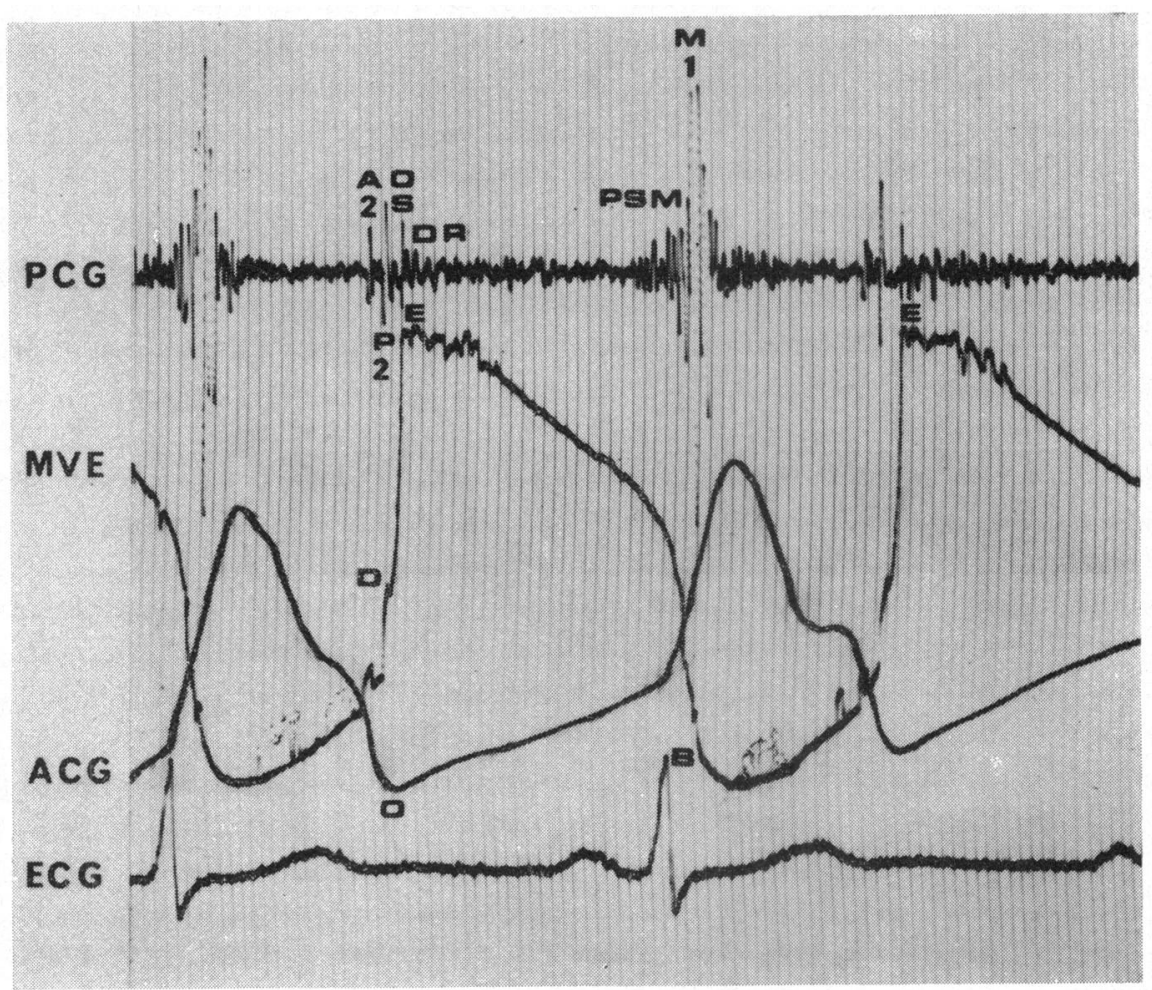

FIG. 4 Mitral stenosis with sinus rhythm. In this patient the valve opening motion is rapidly completed at the $E$ point, which coincides with the opening snap. The diastolic rumble follows immediately and is recorded simultaneously with the diastolic slope of the echocardiogram, which presents dents in its initial part. The presystolic murmur is clearly related to the closing motion of the valve.

backwards and the blood flowing forwards. We think that, in addition to the mitral valve motion, left atrial systole contributes to production of the murmur by increasing the flow velocity through the mitral orifice; thus, the mechanism of the impact of the blood flow against the valve motion is reinforced and begins earlier, just after the peak of the $A$ wave in the echocardiogram. This explains the fact that the presystolic murmur is a constant finding and begins earlier in sinus rhythm than in atrial fibrillation.

Our observations also suggest that the mitral valve closure in early diastole may also contribute to the diastolic rumble in mitral stenosis. It was interesting to note that in all patients the diastolic rumble was not recorded during the time the mitral valve was opening. Like Friedman (1970), we found that the opening motion of the valve usually had two distinct phases. The first one, which is rapid, lasts
20 to $40 \mathrm{msec}$ and ends at the $\mathrm{X}$ point, coinciding with the opening snap of the phonocardiogram; the second one is slow, lasts 20 to $60 \mathrm{msec}$, and ends at the $\mathrm{E}$ point, when the anterior leaflet has moved to the completely open position. This second phase of the opening motion appears simultaneously with the initial part of the filling wave of the apex cardiogram, beginning immediately after the $O$ point (Fig. I, 3, 6, and 7). Therefore, the diastolic rumble would be expected to appear at least during this phase of valve opening, when according to the classical view the prerequisites for production of a murmur exist, i.e. increased blood flow velocity through a narrow mitral orifice. Instead, we found that the diastolic rumble started after the $\mathrm{E}$ point of the echocardiogram, during the diastolic closing motion of the anterior leaflet. These observations suggest that in mitral stenosis the diastolic rumble is probably not caused by the blood flow through the 


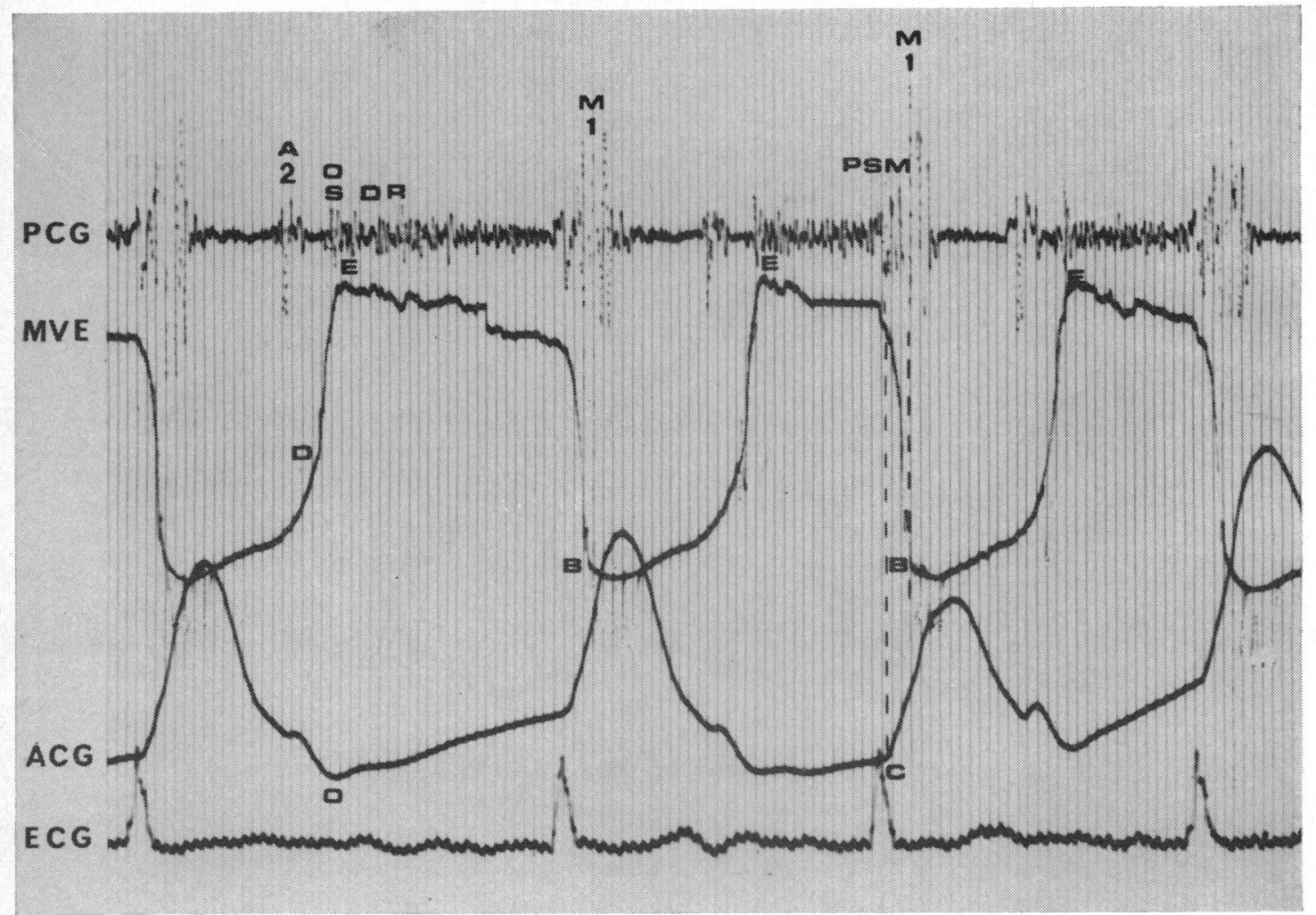

FIG. 5 Mitral stenosis with atrial fibrillation. The diastolic rumble begins with the opening snap and is recorded simultaneously with the 'dented' diastolic slope of the echocardiogram. The $E$ point coincides with the opening snap. A presystolic murmur is more obvious in the cardiac cycle after a short diastolic period. Note the clear relation between the closing motion of the valve and the presystolic murmur which is recorded during preisometric systole $\left(C-M_{1}\right.$, vertical dotted lines).

stenotic orifice, but is the result of the impact of the forward blood flow and the backward closing motion of the mitral valve in early diastole. This would explain the fact that in many patients with mitral stenosis the diastolic rumble begins some time after the opening snap (Tavel, 1972). This probably occurs because at that time there is no backward (closing) movement of the mitral valve. In other patients the beginning of the diastolic rumble coincides with the opening snap; we observed that this occurred in patients with a pliable mitral valve system, in whom the opening motion was completed rapidly at the time the opening snap was recorded, so that again the diastolic rumble appeared only during the diastolic closing motion of the valve.

In calcified mitral stenosis the diastolic rumble is quiet and may disappear despite the increased flow velocity through the narrowed orifice. According to the proposed mechanism the murmur is quiet because the valve does not move sufficiently. Further evidence in favour of our view is that in patients with loud diastolic rumbles the diastolic slope of the mitral valve echocardiogram very often presents distortions or dents, which are always absent in calcified valves. 


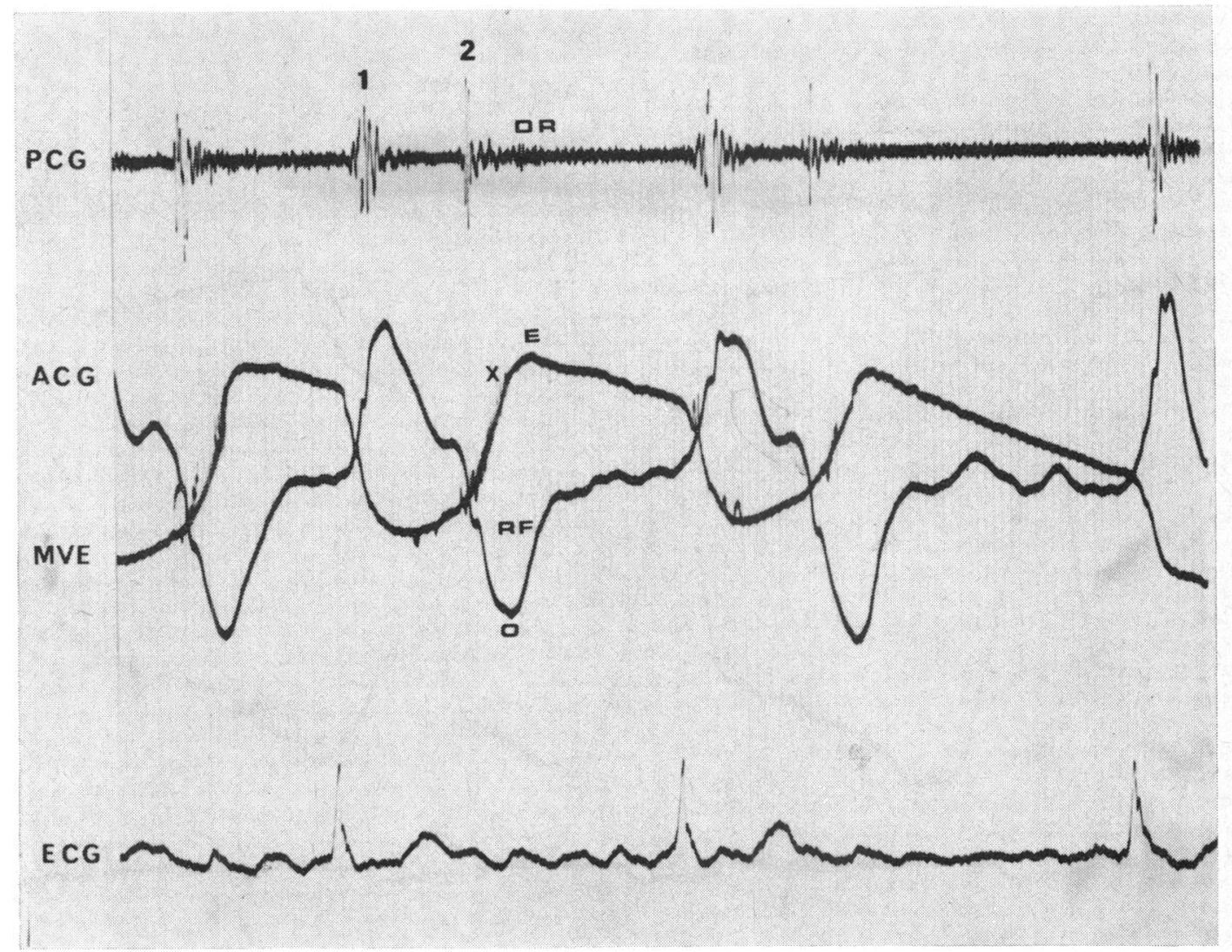

FIG. 6 Calcified mitral stenosis with atrial fibrillation. The echocardiogram is significantly amplified. A very inconspicuous opening snap is recorded simultaneously with the $X$ point. $A$ slow opening motion of the anterior leaflet is noted between the points $X-E$. The diastolic rumble is virtually absent. 


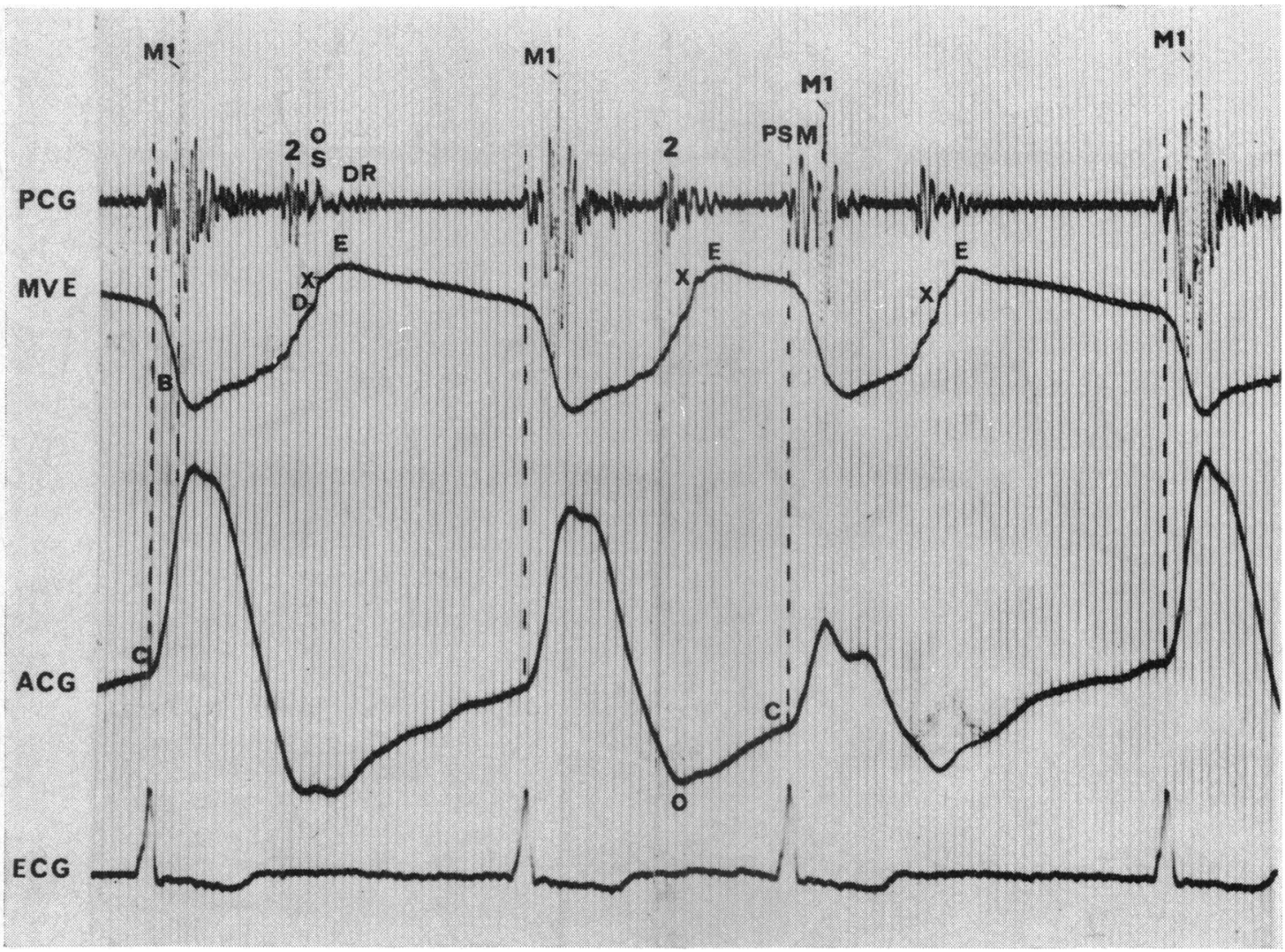

FIG. 7 Mitral stenosis with atrial fibrillation. A quiet presystolic murmur is related to the closing motion of the mitral valve occurring during preisometric systole (after the $C$ point of the apex cardiogram). 
TABLE 2 Data derived from 36 patients with mitral stenosis in atrial fibrillation

\begin{tabular}{|c|c|c|c|c|c|c|c|c|}
\hline \multirow{2}{*}{$\begin{array}{l}\text { Case } \\
\text { No. }\end{array}$} & \multirow[t]{2}{*}{ Sex } & \multirow{2}{*}{$\begin{array}{l}\text { Age } \\
(y r)\end{array}$} & \multirow{2}{*}{$\begin{array}{l}\text { Heart } \\
\text { rate }\end{array}$} & \multirow{2}{*}{$\begin{array}{l}\text { Presystolic } \\
\text { murmur } \\
\text { (crescendo) }\end{array}$} & \multirow{2}{*}{$\begin{array}{l}\mathrm{A}_{2}-\mathrm{OS} \\
\text { interval } \\
\text { (msec) }\end{array}$} & \multicolumn{3}{|c|}{ Mitral valve echocardiogram } \\
\hline & & & & & & $\begin{array}{l}D-X \text { interval } \\
(\mathrm{msec})\end{array}$ & $\begin{array}{l}X-E \text { interval } \\
(m s e c)\end{array}$ & $\begin{array}{l}\text { Diastolic slope } \\
\text { rate } \\
(\mathrm{mm} / \mathrm{sec})\end{array}$ \\
\hline $\mathbf{I}$ & $\mathbf{M}$ & 50 & 61 & + & 100 & 30 & 50 & I0 \\
\hline 2 & $\mathbf{F}$ & 43 & 85 & - & 50 & 40 & 60 & 25 \\
\hline 3 & $\mathbf{M}$ & 48 & 83 & + & 60 & 40 & 30 & 13 \\
\hline 4 & $\mathbf{F}$ & 53 & 87 & + & 75 & 30 & 20 & 19 \\
\hline 5 & $\mathbf{F}$ & 32 & 65 & - & 90 & 40 & 60 & 17 \\
\hline 6 & $\mathbf{F}$ & 50 & 80 & - & 50 & 30 & 20 & 20 \\
\hline 7 & $\mathbf{F}$ & 45 & 62 & - & 50 & 30 & 30 & 17 \\
\hline 8 & $\mathbf{F}$ & 46 & 59 & + & 60 & 40 & 20 & 17 \\
\hline 9 & $\mathbf{M}$ & 38 & 60 & + & 60 & 40 & 40 & 18 \\
\hline 10 & $\mathbf{F}$ & 43 & 85 & - & 75 & 30 & 40 & 13 \\
\hline I I & $\mathbf{M}$ & 50 & 82 & - & 60 & 40 & 60 & 20 \\
\hline 12 & $\mathbf{F}$ & 44 & 63 & - & 100 & 40 & 60 & II \\
\hline 13 & $F$ & 45 & 63 & - & I10 & 30 & 40 & 15 \\
\hline 14 & $\mathbf{M}$ & 54 & 86 & - & 60 & 20 & 60 & 12 \\
\hline 15 & $\mathbf{F}$ & 31 & 62 & - & 70 & 20 & 30 & 10 \\
\hline 16 & $\mathbf{M}$ & 35 & 58 & - & 55 & 40 & 40 & 8 \\
\hline 17 & $F$ & 35 & 65 & + & 90 & 40. & 40 & 10 \\
\hline 18 & $\mathbf{F}$ & 44 & 67 & - & 90 & $40^{\circ}$ & 30 & 15 \\
\hline 19 & $\mathbf{F}$ & 25 & 72 & - & 80 & 30 & 50 & 18 \\
\hline 20 & $\mathbf{F}$ & 55 & 82 & + & 95 & 20 & 60 & 8 \\
\hline 21 & $\mathbf{F}$ & 65 & 78 & + & 100 & 20 & 50 & I0 \\
\hline 22 & $\mathbf{F}$ & 57 & 60 & - & 100 & 20 & 60 & 15 \\
\hline 23 & $\mathbf{F}$ & 50 & 85 & - & 80 & 40 & 40 & 21 \\
\hline 24 & $\mathbf{M}$ & 53 & $8 I$ & + & IIO & - & - & 25 \\
\hline 25 & $\mathbf{M}$ & 46 & 92 & - & 80 & 40 & 60 & 8 \\
\hline 26 & $\mathbf{F}$ & 50 & 95 & - & 85 & 40 & 40 & 33 \\
\hline 27 & $\mathbf{F}$ & 65 & 88 & - & 80 & 20 & 40 & 19 \\
\hline 28 & $\mathbf{F}$ & 35 & 76 & - & 50 & 40 & 40 & 32 \\
\hline 29 & $\mathbf{F}$ & 57 & 80 & - & 95 & - & - & 18 \\
\hline 30 & $\mathbf{F}$ & 47 & 85 & - & 70 & 30 & 50 & 12 \\
\hline 31 & $F$ & 46 & 65 & + & 85 & - & - & 15 \\
\hline 32 & F & 42 & 72 & - & 75 & 20 & 60 & 16 \\
\hline 33 & $\mathbf{F}$ & 59 & 85 & - & 65 & 40 & 40 & 8 \\
\hline 34 & $\mathbf{F}$ & 36 & 82 & - & 80 & 30 & 40 & 30 \\
\hline 35 & $\mathbf{F}$ & 49 & 73 & - & 120 & - & - & 14 \\
\hline 36 & $\mathbf{F}$ & 51 & 70 & - & 75 & - & - & 8 \\
\hline
\end{tabular}

\section{References}

Criley, J. M., Feldman, I. M., and Meredith, T. (I97I). Mitral valve closure and the crescendo presystolic murmur. American fournal of Medicine, 51, 456.

Criley, J. M., and Hermer, A. J. (197I). Crescendo presystolic murmur of mitral stenosis with atrial fibrillation. New England fournal of Medicine, 285, 1294.

Edler, I. (1967). Ultrasoundcardiography in mitral valve disease. American fournal of Cardiology, 19, 18.

Fortuin, N. J., and Craige, E. (1972). On the mechanism of the Austin Flint murmur. Circulation, 45, 558.

Fortuin, N. J., and Craige, E. (1973). Echocardiographic studies of genesis of mitral diastolic murmurs. British Heart fournal, 35, 75.

Friedman, N. J. (1970). Echocardiographic studies of mitral valve motion. Genesis of the opening snap in mitral stenosis. American Heart fournal, 80, 177.

Lakier, J. B., Pocock, W. A., Gale, G. E., and Barlow, J. B. (1972). Haemodynamic and sound events preceding first heart sound in mitral stenosis. British Heart fournal, 34, II 52.

Leo, T., and Hultgren, H. (1959). Phonocardiographic characteristics of tight mitral stenosis. Medicine, 38, 85 .

Nichols, H. T., Likoff, W., Goldberg, H., and Fuchs, $M$. (1956). The genesis of the presystolic murmur in mitral stenosis. American Heart fournal, 52, 379.

Ongley, P. A., Sprague, H. B., and Rappaport, M. B. (1955). The diastolic murmur of mitral stenosis. New England fournal of Medicine, 253, 1049.

Tavel, M. (1972). Clinical Phonocardiography and External Pulse Recordings. Year Book Medical Publishers, Chicago.

Willems, J. L., De Geest, H., and Kesteloot, H. (197I). On the value of apex cardiography for timing intracardiac events. American fournal of Cardiology, 28, 59.

Requests for reprints to Dr. Pavlos Toutouzas, Io Likiou Street, Athens T.138, Greece. 